Original Research Article

\title{
A donor hemovigilance study: evaluation of adverse reactions to blood donors at tertiary care teaching hospital
}

\author{
Sheetal M. Savaliya*, Anil P. Singh, Kiran G. Piparva
}

\begin{abstract}
Department of Pharmacology, P.D.U. Government Medical College, Rajkot, Gujrat, India
\end{abstract}

Received: 10 January 2019

Revised: 08 May 2019

Accepted: 13 May 2019

*Correspondence to:

Dr. Sheetal M. Savaliya, Email: shitalsavaliya1010@ gmail.com

Copyright: $\odot$ the author(s), publisher and licensee Medip Academy. This is an openaccess article distributed under the terms of the Creative Commons Attribution NonCommercial License, which permits unrestricted noncommercial use, distribution, and reproduction in any medium, provided the original work is properly cited.

\begin{abstract}
Background: Donor hemovigilance is an important aspect of the hemovigilance system and contributes to decrease the blood donor's complications and improving blood donor safety and functioning of blood bank. Reporting of adverse reactions associated with blood donations has been covered under National blood donor vigilance programme. This study was carried out to estimate the adverse events in blood donors and to promote their safety.

Methods: The study was conducted over a period of 6 months, from 1st January 2017 to 30th June 2017 after getting approval from institutional ethics committee at tertiary care teaching hospital. Prior informed consent was obtained and donor confidentiality was ensured. The donors were observed for adverse event during or after donation. For delayed reactions, donors were requested to contact the researcher or designated departmental staff. Data was collected in case record form. Data entry was done in excel 2013 and appropriate Statistical test (chi square) was applied.
\end{abstract}

Results: During study period total 7970 donors were registered, out of which $53.27 \%$ donors have donated their blood in blood camps and $46.72 \%$ have in blood bank. Incidence of donor reactions was $1.54 \%$. Incidence of adverse reaction was higher at blood camps $(58.53 \%)$. Authors found highest number of cases of mild vaso vagal type reactions (53\%). Other types of reactions observed were painful arm, hematoma, delayed bleeding, tingling and moderate type of vaso vagal reaction.

Conclusions: Authors did not find any major serious events like convulsion, thrombophlebitis or arterial puncture during study period. It considers that safety of donors was maintained.

Keywords: Donor hemovigilance, Donor reactions, Donors safety

\section{INTRODUCTION}

Although blood donation is a relatively safe procedure around $2 \%$ to $3 \%$ of blood donors experience adverse events. ${ }^{1}$ Donor reactions may negatively affect donor health, donor satisfaction as well donor recruitment, and return rate. Donor hemovigilance is an important aspect of the hemovigilance system and contributes to decrease the donor reactions and improving blood donor safety and functioning of blood bank. ${ }^{1,2}$ Reporting of adverse reactions associated with blood donations has been covered under National blood donor vigilance programme(NBDVP) which was launched on $14^{\text {th }}$ June 2015 on World's blood donor day at science city Kolkata under the ambit of hemovigilance programme of India. Donor-vigi software was launched on $14^{\text {th }}$ June 2016 at Darjeeling. ${ }^{2}$ in India hemovigilance, is not fully developed. Only few institutional reports are available regarding blood donor hemovigilance. ${ }^{2,3}$ Blood donor hemovigilance is an important aspect of the hemovigilance system and contributes to decrease the donation complications and improving blood donor safety and functioning of blood 
bank. ${ }^{4}$ The safety of the entire transfusion chain, i.e. from the donor to the recipients needs monitoring. This can only be achieved by careful observation and analysis of adverse events, hence hemovigilance, which is defined as "A set surveillance procedures, from the collection of blood and its components to the follow-up of recipients to collect and assessment information on unexpected or undesirable effects resulting from the therapeutic use of labile blood products and to prevent their occurrence or recurrence". 5 Hence our aim of the study was to estimate the adverse events (AE) in blood donors in order to promote donors safety and contribute towards the initiation of an institutional hemovigilance system.

\section{METHODS}

The study was conducted over a period of 6 months, from 01 January 2017 to 30 June 2017 after getting approval from institutional ethics committee at tertiary care teaching hospital. Prior informed donor consent was obtained, and donor confidentiality were ensured. The donors were observed during or after donation for any adverse event.
For delayed adverse reactions, donors were requested to contact the researcher or designated departmental staff. Author enrolled all blood donors (total 123) who experienced reaction following blood donation. Data was collected and recorded in a case record form. Data entry was done in excel 2013 and appropriate Statistical test (chi square) was applied.

Inclusion criteria was, all blood donors with adverse reactions after blood donation in the blood bank and blood donation camps were included. Exclusion criteria was all blood donors who didn't experience any type of adverse reaction were excluded.

\section{RESULTS}

During the study period total 7970 blood donors have donated their blood and out of which total 123 donors experienced adverse reaction. As shown in Table 1, Authors found more donors at camp and of voluntary type, while in case of blood bank replacement type of donors were found.

Table 1: Types and site of blood donation.

\begin{tabular}{|llll|}
\hline $\begin{array}{l}\text { Donation site/Type of blood } \\
\text { donors }\end{array}$ & $\begin{array}{l}\text { Donation in camp } \\
\mathbf{n} \mathbf{1 = 4 2 4 6}(\mathbf{5 3 . 2 7} \%)\end{array}$ & $\begin{array}{l}\text { Donation in blood bank } \\
\mathbf{n} 2=3724(\mathbf{4 6 . 7 2 \%})\end{array}$ & $\begin{array}{l}\text { Total } \\
\mathbf{N = 7 9 7 0}(\mathbf{1 0 0} \%)\end{array}$ \\
\hline Voluntary donors & 4246 & 24 & $4270(53.57 \%)$ \\
\hline Replacement donors & 0 & 3700 & $3700(46.42 \%)$ \\
\hline
\end{tabular}

Table 2: Socio demographic details of donors with adverse reactions ( $N=123$, Incidence-1.54\%).

\begin{tabular}{|c|c|c|c|}
\hline $\begin{array}{l}\text { Socio demographic } \\
\text { parameters }\end{array}$ & $\begin{array}{l}\text { Adverse reactions (In } \\
\text { blood Camps) } \\
\mathbf{7 2}(58.53 \%)\end{array}$ & $\begin{array}{l}\text { Adverse reactions (In } \\
\text { blood Bank) } \\
51(41.46 \%)\end{array}$ & $\begin{array}{l}\text { Total reactions } \\
123(100 \%)\end{array}$ \\
\hline \multicolumn{4}{|l|}{ Age } \\
\hline $18-40$ years & 58 & 43 & $101(82.11 \%)$ \\
\hline$>40$ years & 14 & $\mathrm{O} 8$ & $22(17.88 \%)$ \\
\hline \multicolumn{4}{|l|}{ Gender } \\
\hline Male & 58 & 40 & $98(79.67 \%)$ \\
\hline Female & 14 & 11 & $25(20.32 \%)$ \\
\hline Weight & & & $P$ value- 0.00006 \\
\hline $45-50 \mathrm{~kg}$ & 53 & 22 & $75(60.97 \%)$ \\
\hline$>50 \mathrm{~kg}$ & 19 & 29 & $48(39.02 \%)$ \\
\hline \multicolumn{4}{|c|}{ Amount of blood donated } \\
\hline $350 \mathrm{ml}$ & 62 & 46 & $108(87.80 \%)$ \\
\hline $450 \mathrm{ml}$ & 10 & 5 & $15(12.19 \%)$ \\
\hline \multicolumn{4}{|c|}{ Frequency of donation } \\
\hline First time donation & 11 & 20 & $31(25.20 \%)$ \\
\hline Repeat donation & 62 & 31 & $91(73.98 \%)$ \\
\hline
\end{tabular}

As shown in Table 2, Authors found more adverse reactions at blood camp $(58.53 \%)$ in comparison to blood bank and more adverse events in male $79.67 \%$ compare to female $(20.32 \%)$ (Authors found significant $\mathrm{p}$ value by chi square test). Most of the blood donors have donated 350 $\mathrm{ml}$ of blood. Authors divided total 123 adverse reaction 
into two types (Figure 1).

- Needle injury related reactions: It includes painful arm, hematoma, delayed bleeding, tingling and numbness (Incidence-44.71\%).

- Vasovagal related reactions: It includes cold feeling, black clouding, sweating, nausea, giddiness, vomiting, hypotension and bradycardia. (Incidence$55.28 \%)$.

Figure 1 showing various types of donor reactions and its percentages, Authors found $53 \%$ of mild vasovagal type of reactions and $3 \%$ of moderate vasovagal type reaction. In needle related reactions, Authors found 20\% painful arm, $12 \%$ hematoma, $9 \%$ delayed bleeding and $3 \%$ of tingling and numbness. All the types of reactions were observed higher in blood camps than blood bank except painful arm which was higher at blood bank (15.68\%) (Table 3).

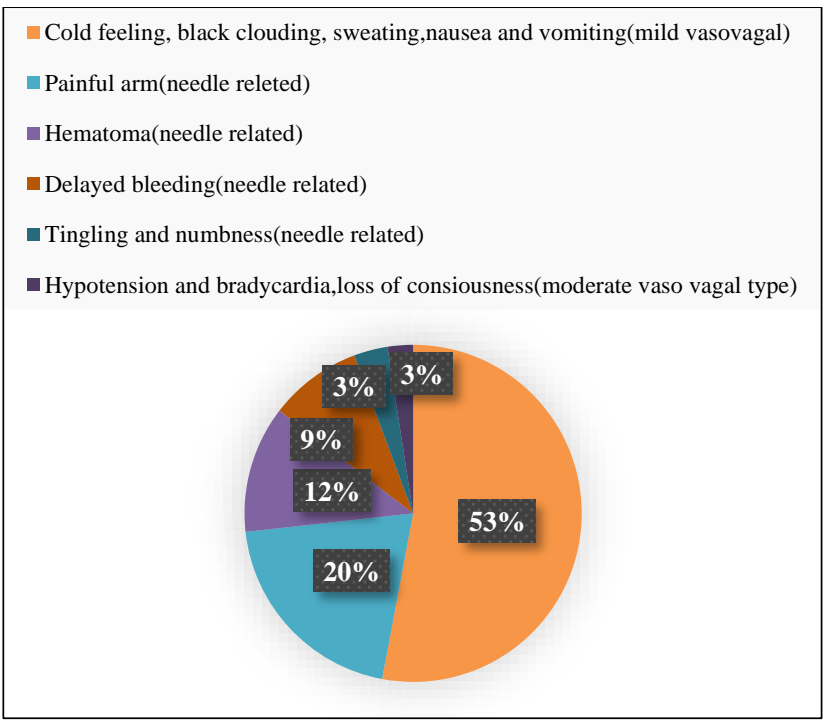

Figure 1: various types of donor reactions.

Table 3: Comparison between various types of adverse reactions in blood camps and blood bank.

\begin{tabular}{|c|c|c|}
\hline Donor reaction & $\begin{array}{l}\text { Reaction } \\
\text { occurred at } \\
\text { blood camp }\end{array}$ & $\begin{array}{l}\text { Reactions } \\
\text { occurred at } \\
\text { blood bank }\end{array}$ \\
\hline Painful arm & $13.9 \%$ & $15.68 \%$ \\
\hline Hematoma & $13.9 \%$ & $9.8 \%$ \\
\hline Delayed bleeding & $12.5 \%$ & $5.9 \%$ \\
\hline Tingling and numbness & $5.5 \%$ & $14 \%$ \\
\hline $\begin{array}{l}\text { Mild vaso vagal } \\
\text { reactions }\end{array}$ & $50 \%$ & $31.38 \%$ \\
\hline $\begin{array}{l}\text { Hypotension and } \\
\text { bradycardia }\end{array}$ & $4.16 \%$ & $4 \%$ \\
\hline
\end{tabular}

Authors observed highest number of adverse reactions $33.33 \%$ which occurred immediately after donation at blood camp and $25.50 \%$ at blood bank. Offsite reaction was observed less in number (Table 4).
Table 4: Occurrence of reactions in relation to time.

\begin{tabular}{|lll|}
\hline $\begin{array}{l}\text { Timing of } \\
\text { reaction/reaction } \\
\text { site }\end{array}$ & $\begin{array}{l}\text { Reactions in } \\
\text { blood camp } \\
(\mathbf{5 8 . 5 3 \% )}\end{array}$ & $\begin{array}{l}\text { Reactions at } \\
\text { blood bank } \\
(\mathbf{4 1 . 4 6 \% )}\end{array}$ \\
\hline $\begin{array}{l}\text { Reaction occurred } \\
\text { during donation }\end{array}$ & $16.67 \%$ & $27.45 \%$ \\
\hline $\begin{array}{l}\text { Reaction occurred } \\
\text { immediately after } \\
\text { donation }\end{array}$ & $33.33 \%$ & $25.50 \%$ \\
\hline $\begin{array}{l}\text { Reactions occurred } \\
\text { within 1 hour }\end{array}$ & $25 \%$ & $25.50 \%$ \\
\hline $\begin{array}{l}\text { Reactions occurred } \\
\text { offsite }\end{array}$ & $25 \%$ & $21.57 \%$ \\
\hline
\end{tabular}

\section{DISCUSSION}

Rate of adverse reactions related to blood donation to be low $(1.54 \%)$ even when considering all mild reactions. Similar rate of reactions found in other studies irrespective of severity. ${ }^{3}$ Majority of blood donation at camp was voluntary type and at blood bank it was replacement type as expected. In both type of blood donation, donation rate was higher in male than female, but reaction rate was higher in females. Donor reaction rate was higher in blood camps which was in contrast to the Agnihotri et al. study where donors at blood bank suffered more adverse reactions than blood camp donors. ${ }^{3}$ The probable reason for this difference might be that most of the donors in the present study were voluntary and had donated in outdoor voluntary blood donation camps and providing environment (temperature, humidity) as hostile and comfortable as inside the blood bank was usually not possible. Moreover, in camps sight of donors suffering adverse reaction creates anxiety and apprehension in nearby donors, especially younger age group. Our study observed that adverse events during blood donation were higher in young and repeat donors which was in contrast to Harkin R et al, and Eder et al, studies.,

The adverse reactions that occur in donors can be divided into local reactions and systemic reactions.

1) Local reactions occur predominantly because of problems related to venous access. They are usually haematomas due to extravasation from the veins, caused by incorrect placement of the needle during the venipuncture, Pain, hyperaemia and swelling may develop at the site of the extravasation. In most cases, these are reactions that do not require any treatment. Local phlebitis and thrombophlebitis and arterial puncture are more serious reactions but are very rare.

2) The systemic reactions, in contrast to the local reactions, can be divided into mild to severe. In most cases, they are vaso-vagal reactions that can be triggered by the pain of the venipuncture, by the donor seeing his or her own blood, by the donor seeing another donor unwell, by the anxiety and state of tension of undergoing the donation, etc. 
The systemic reactions are characterised by the appearance of pallor, sweating, dizziness, gastrointestinal disorders, nausea, hypotension, and bradycardia. Therapeutic intervention must be swift, otherwise this clinical picture, typical of a vasovagal reaction, will progress into an episode of syncope, of variable severity, which may or may not be complicated by the onset of tonic clonic muscle spasms (convulsive syncope), accompanied by vomiting and loss of sphincter control.

During or after blood donation, if blood donors presented with anxiety, tachypnoea, tachycardia, pallor sweating, dizziness, nausea / vomiting, cold or clammy skin, it was categorized into mild category. If they presented with signs and symptoms of transient loss of consciousness and those who presented with mild reaction but for more than 15 minutes, they were categorized into moderate category. Donors presenting with convulsion or incontinence (fecal/urine) were placed severe category.

Most common types of reactions were vasovagal reactions and hematoma. Vasovagal reactions found in this study were lower than reported in other studies. ${ }^{6-8}$ The pattern may be explained by the possible under-reporting of late reactions, in particular mild vasovagal reactions. Only mild and moderate vasovagal reactions were observed in this study. Nerve injury that leads to permanent or some degree of disablement which is less frequent in this study than others, but the rate of reactions leading to minor disablement in our study was consistent with previous report. ${ }^{9,10}$

A very few numbers of donors experienced long-term morbidity in our study. Most donors with long-term morbidity had complaints of arm pain when they were moving it, radiating pain or sensory changes (tingling and numbness) extending to the forearm, hand or fingers, hematoma and some had delayed bleeding. Hardly any of these donors were eventually seemed disabled due to a donation-related complication. The degree of disablement in general was probably not severe. The symptoms were not interfering with the donors' daily activities and therefore can be considered negligible. ${ }^{11}$

The registration of delayed donor complications was based on call back and late-developing reactions are therefore only identified if the donor returns with a complaint. Thus, late events could be underreported.

\section{CONCLUSION}

Incidence of adverse reactions following blood donation was low (1.54\%) and of "mild" severity. It considers that safety of donors was maintained.

\section{ACKNOWLEDGEMENTS}

Authors would like to thank Dr. Gauravi Dhruva, professor and head department of pathology, PDUMC Rajkot, India.

Funding: No funding sources

Conflict of interest: None declared

Ethical approval: The study was approved by the Institutional Ethics Committee

\section{REFERENCES}

1. Das SC. Donors Hemovigilance: An Institutional Study. Int J Sci Res. 2016;6(5):203-6.

2. Bisht A, Singh S, Marwaha N. National blood donor vigilance programme India. Asian J Transfus Sci. 2016;10(1):1-2.

3. Agnihotri N, Marwaha N, Sharma R. Analysis of adverse events and predisposing factors in voluntary and replacement whole blood donors. A study from North India: Asian J Transfus Sci. 2012;6(2):155-60.

4. Harkin R, Lessig M. Reaction incidence among teenaged first time and repeat whole blood and apheresis donors. Transfusion. 2007;47(3):105A.

5. Eder AF, Dy BA, Kennedy JM, Notari IV EP, Strupp A, Wissel ME, et al. The American Red Cross Donor Hemovigilance program, complications of donation reported in 2006. Transfusion. 2008;48(9):1809-19.

6. Caffrey EA, Butler M, Bissell L, Bowden M, Fry R. Establishing a national adverse event reporting system for blood donors- a prospective study of 1.8 million attendances in England and North Wales. Vox Sang. 2005; $1: 109-14$.

7. Newman BH. Blood donor complications after whole blood donation. Curr Opin Hematol. 2004;11(5):33945.

8. Newman BH. Vasovagal reactions and body weight: findings in high and low risk populations. Transfusion. 2003;43(8):1084-88.

9. Horowitz SH. Venipuncture-induced nerve injury: a review. J Neuropathic Pain Symptom Palliation. 2005;1(1):109-14.

10. Newman BH, Waxman DA. Blood donation-related neurologic needle injury. Evaluation of 2 years' worth of data from a large blood center. Transfusion. 1996;36(3):213-5.

11. Abhishekh B, Mayadevi S, Usha KC. Adverse reactions to blood donation. Innovative $\mathrm{J}$ Med Health Sci. 2013;3(4):158-60.

Cite this article as: Savaliya SM, Singh AP, Piparva KG. A donor hemovigilance study: evaluation of adverse reactions to blood donors at tertiary care teaching hospital. Int $\mathbf{J}$ Basic Clin Pharmacol 2019;8:1538-41. 